\title{
متطلبات تطبيق الإدارة الإلكترونية في الجامعة
}

\author{
إعـــــداد \\ د/ ننسى احمد فؤ اد \\ مدرس أصول التربية \\ كلية التربية بقتا - جامعة جنوب الوادي \\ nancy.ahmed@edu.svu.edu.eg \\ أ.د/ محمد النصر حسن محمد \\ أستاذ و رئيس قسم أصول التربية \\ كلية التربية بقنا - جامعة جنوب الوادي \\ mohamed.ahmed1@edu.svu.edu.eg
}

$$
\begin{aligned}
& \text { أ/ أم هاثم محمود محمد } \\
& \text { باحثة ماجستير - قسم أصول التربية } \\
& \text { كلية التربية بقنا - جامعة جنوب الوادى } \\
& \text { om@edu.svu.edu.eg }
\end{aligned}
$$




$$
\text { متطلبات تطبيق الإدارة الإلكترونية في الجامعة }
$$

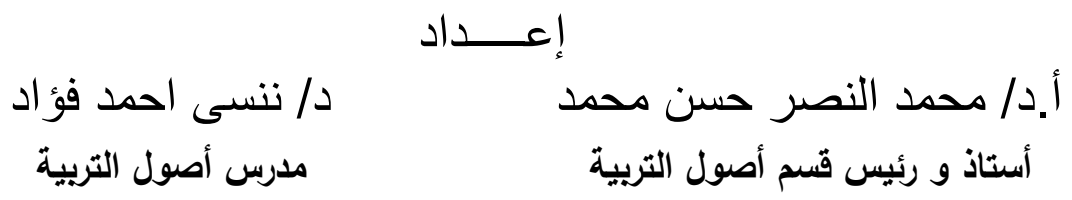

كلية التربية بقتا - جامعة جنوب الوادي التوليه

nancy.ahmed@edu.svu.edu.eg كلية التربية بقنا - جامعة جنوب الوادي mohamed.ahmed1@edu.svu.edu.eg

$$
\begin{aligned}
& \text { أر أم هاثم محمود محمد } \\
& \text { باحثة ماجستير - قسم أصول التربية } \\
& \text { كلية التربية بقنا - جامعة جنوب الوادى } \\
& \text { om@edu.svu.edu.eg }
\end{aligned}
$$

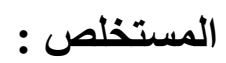

تمنل الادارة الاكترونية تحولاً شاملاً في الدفاهيم والنظريات والممارسات والتشريعات التي تقوم عليها الادارة النقليدية و هدفت الدراسة الحالية إلى تحديد المنطلبات التي نواجه تطبيق الإدارة الإككترونية في الجامعة ، وتتاولت الدراسة مفهوم الإدارة الالكترونية وبيان أهداف الإدارة الالكترونية وكذلك المنطلبات التثريعية والبشرية والثقنية والأمنية والمالية لنطبيق الادارة الالكترونية، والمهارات المتعلقة بمشروع الإدارة الاكترونية، والتعرف على كيفية الانتقال من ولنه الادارة التقليدية الى الادارة الالكترونية بصورة سليمة وناجحة داخل الجامعة.

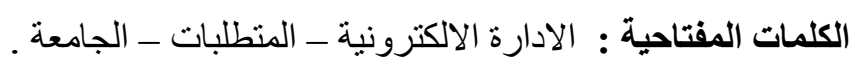


متطلبات تطبيق الادارة الاكترونية فى الجامعة

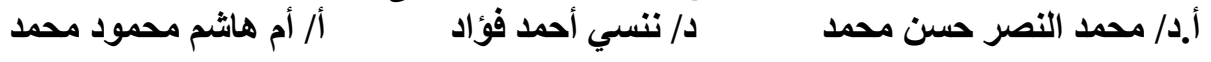

\title{
Requirements for the Application of Electronic Administration in the University
}

\section{Prof.Dr.Mohamed Elnasr Hassan}

Education Assets Department

Faculty of Education in Qena

South Valley University

mohamed.ahmed1@edu.svu.edu.eg

\author{
Dr.Nansy Ahmed Fouad \\ Education Assets Department \\ Faculty of Education in Qena \\ South Valley University \\ nancy.ahmed@edu.svu.edu.eg
}

\section{Om Hashem Mahmoud Mohamed \\ Education Assets Department \\ Faculty of Education in Qena \\ South Valley University \\ om@edu.svu.edu.eg}

\begin{abstract}
:
The study focused on the concept of electronic administration and the objectives of electronic administration as well as the legislative, human, technical, security and financial requirements for the application of electronic administration, And skills related to the electronic management project, and to learn how to move from traditional to electronic management in a sound and successful manner within the university.
\end{abstract}

Keywords: electronic administration - requirements - university. 
إن ادخال تقنيات المعلومات والاتصال هو ثورة حقيقية في الادارة، لما يحدث من تغيير

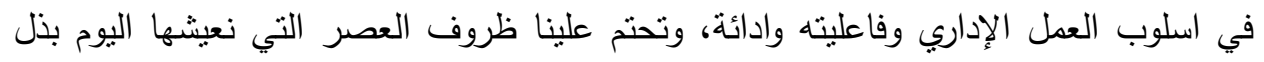
مجهودات كبيرة في سبيل إنجاز الاعمال ذات المنطلبات الكثيرة وفى وقت قصير ومن هنا تبرز

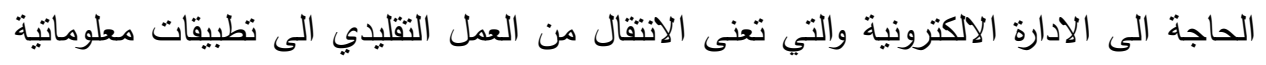

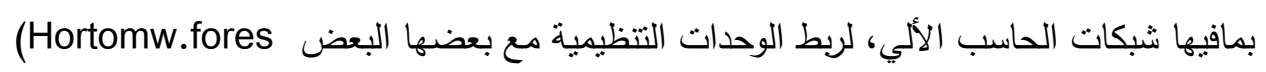
2001, 58)

كما أن هذه الثورة العلمية الهائلة التي غزت جميع المجالات، تحمل في طياتها

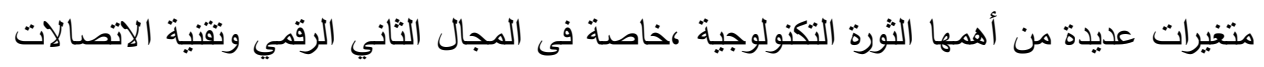
والمعلومات، فلقد دخل العالم هذا القرن في حقبة جديدة من التغيير بسبب إنتاج الكميات الكبيرة

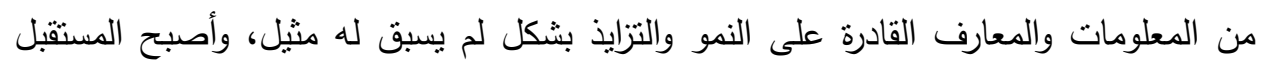

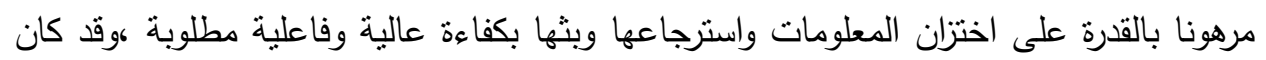

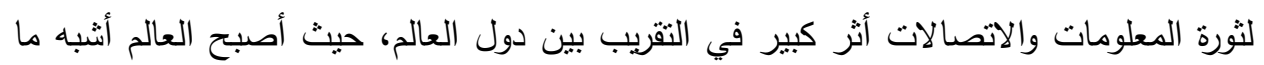

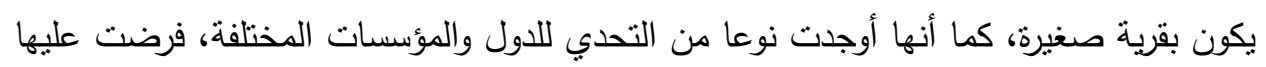

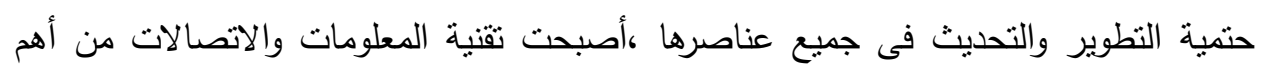

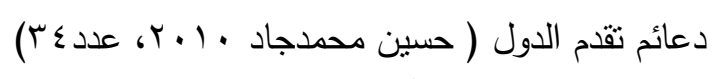

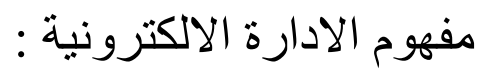

مفهوم الادارة الاككترونية مصطلح حديث، ظهر كنتيجة لثثرة المعلومات والاتصالات التي تعيشها البشرية حاليا خصوصا بعد ظهور ما يسمى بالاقتصاد الرقمي وكنتيجة لحداثة هذا لاديا المصطلح واستخداماته فيما بين القطاع العام والقطاع الخاص، فقد ظهر بعال بعدة مسميات كالإدارة

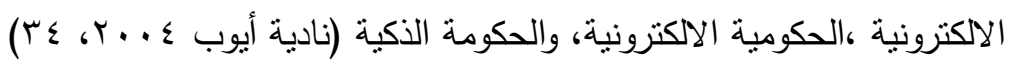

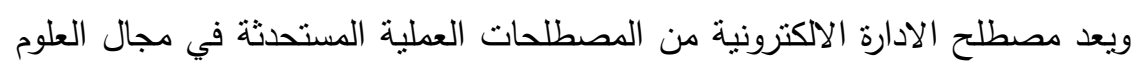

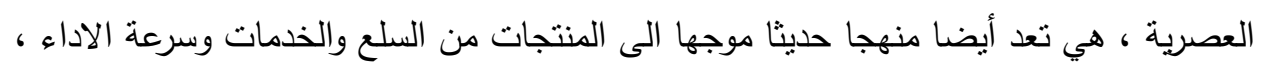
ويعتمد على استخدام شبكة متقدمة ،باستخدام الحاسوب وشبكات الأنترنت في إنجاز الاعمال

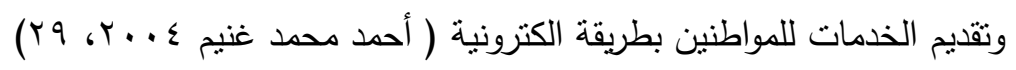

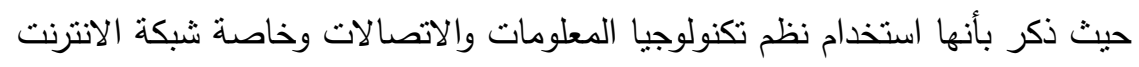

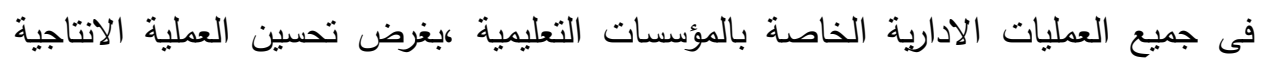

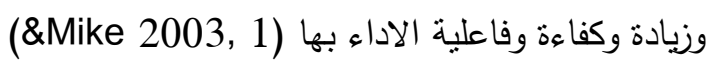


وعرفها كل من (هويكنز ،وماركهام )بأنها: "تطبيق متميز للتقنيات المعتمد ة على

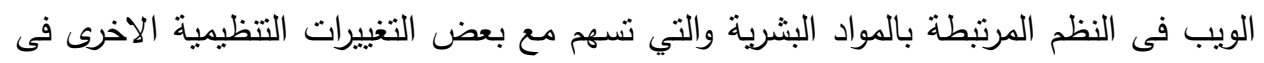

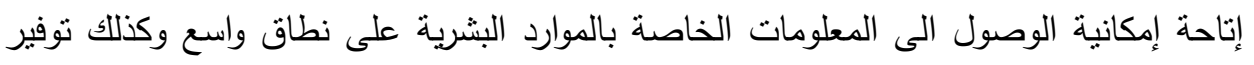

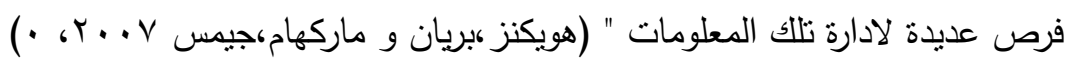

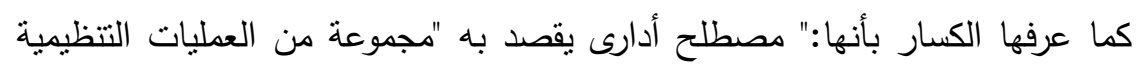

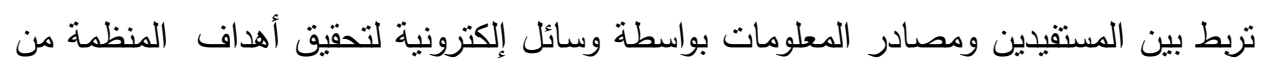

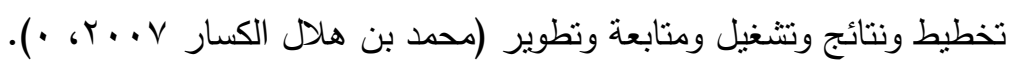

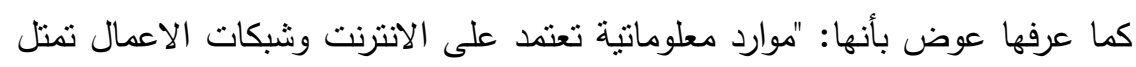

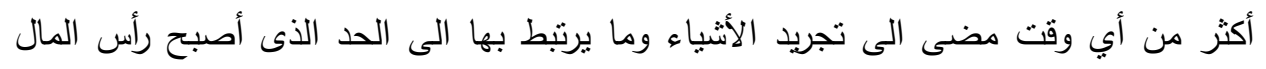

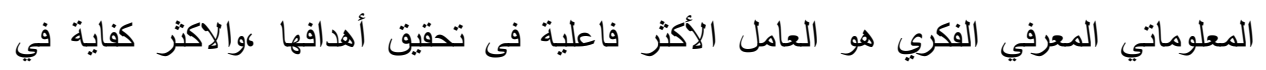

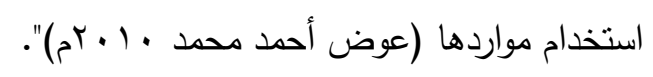

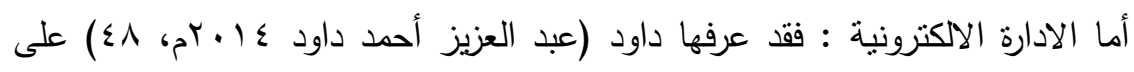

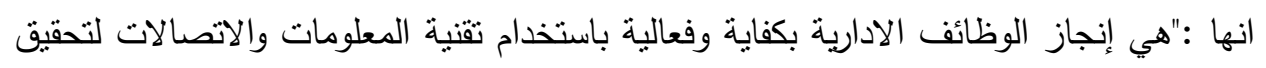

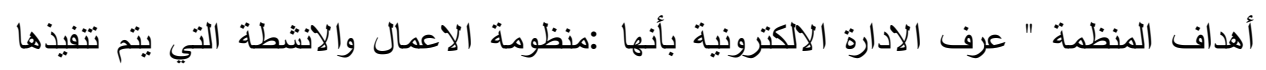

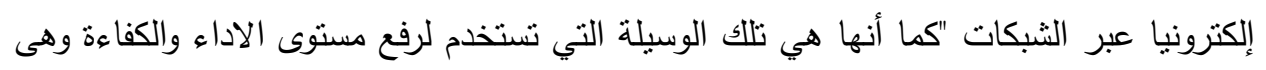

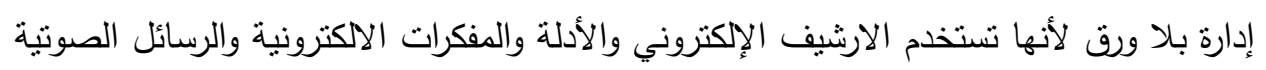

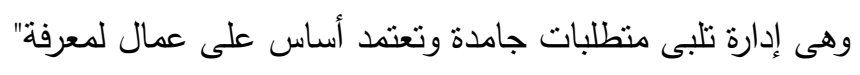
وعرفت بخش الادارة الاككترونية:" هي إنجاز الوطائف الادارية بكفاية وفعالية باستخدام

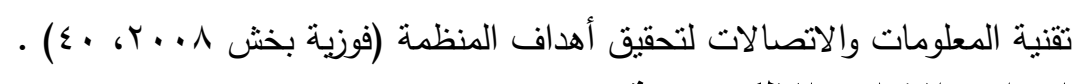
اهداف الادارة الالكترونية :

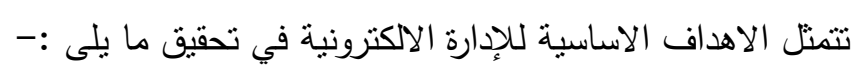

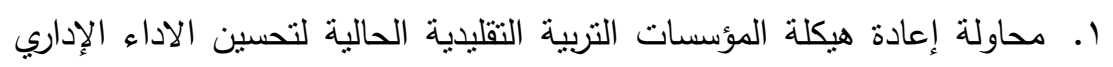

التقليدي المتمنل في كسب الوقت وتقليل التكلفة اللازمنين لإنجاز المعاملات وفق تطور مفهوم الادارة الاكترونية ،إعادة النظر فى الموارد البشرية المتاحة

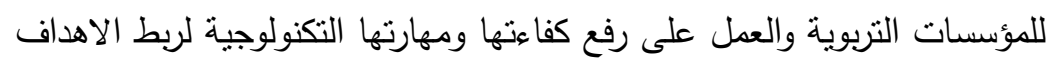

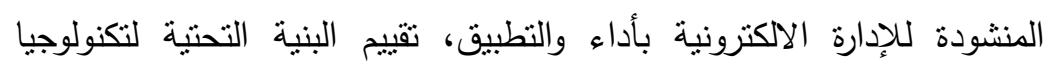
المعلومات والاتصالات وتحريرها ـ لكى نستجيب ومنطلبات الخدمات الأزمة

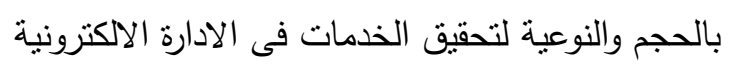


r. وتطرق بعض الباحثين والمفكرين الى أهداف الإدارة الالكترونية في المؤسسات

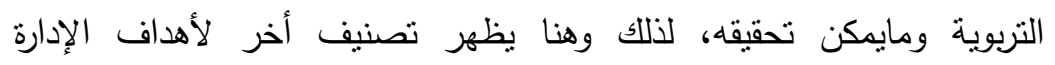

$$
\text { الالكترونية }
$$

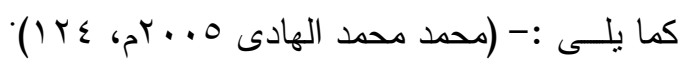

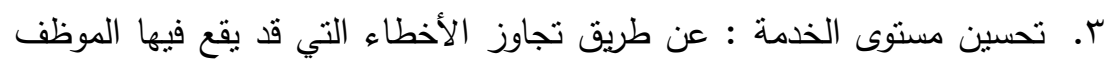

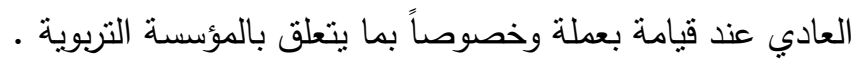

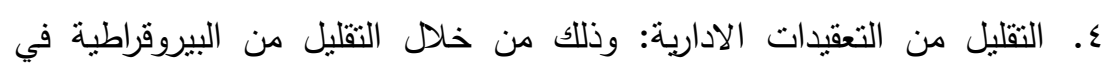

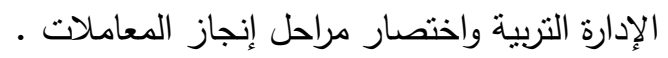
ه. تخفيض التكاليف :ومن ذللك إمكانية حصول الافراد على المعلومات والبيانات

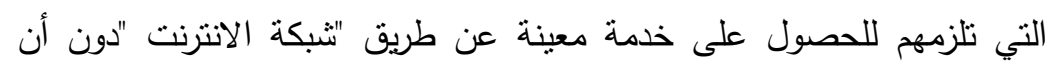
يكلف نفسه مراجعة المؤسسة التزبوية . T. تحقيق الإفادة القصوى للعاملين في المؤسسة التربوية :ومن ذلك إتباع اسلوب التهبه

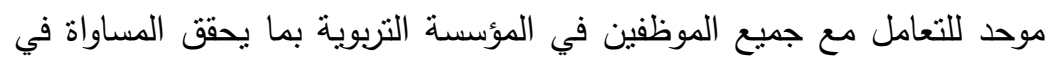

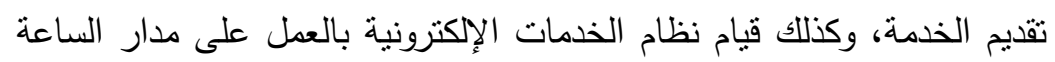

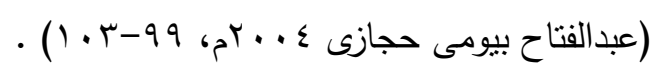

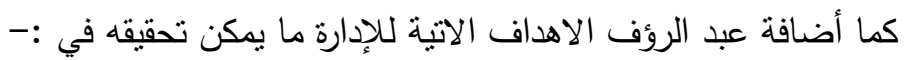

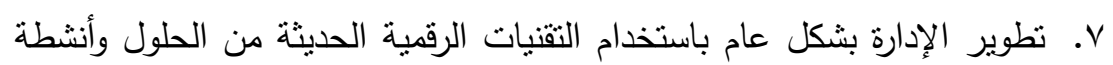

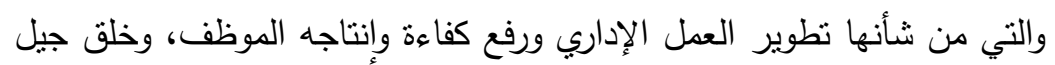

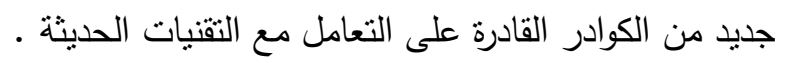

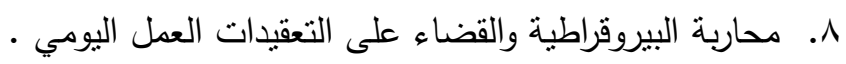

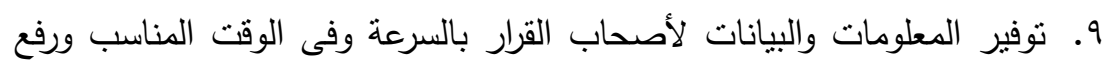

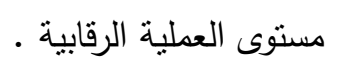

• (.تقليل تكاليف التشغيل من خلال خفض الملفات والخزائن لحفظها وكميات .

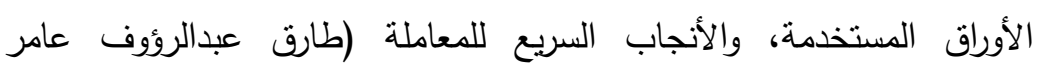

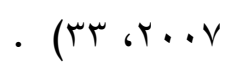

كما أضاف الهوش الأهداف الأتية للإدارة الإكترونية :

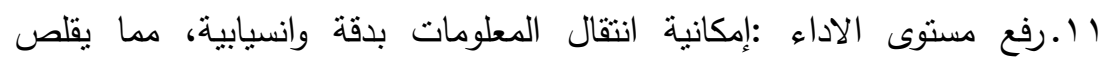

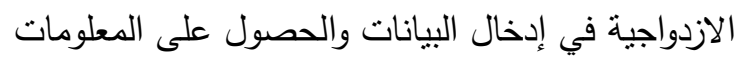


متطلبات تطبيق الادارة الاككترونية فى الجامعة

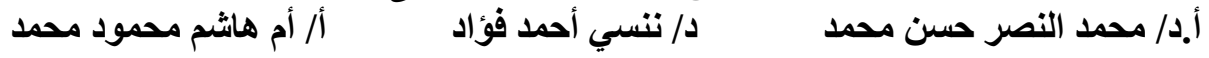

r ا.زيادة دقة البيانات : نظراً لتوفير إمكانية الحصول على المعلومات المطلوبة من

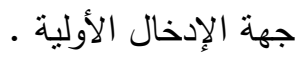

با.تلخيص الإجراءات الإدارية

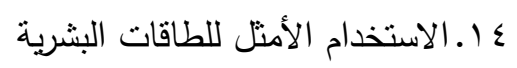

10 أزيادة الإنتاجية وخفض التكلفة في الأداء

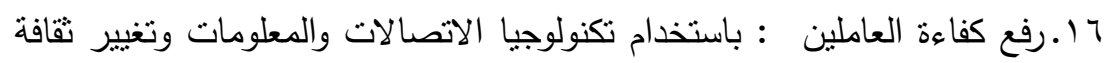

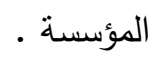

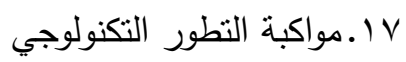

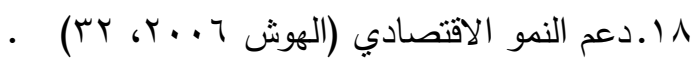

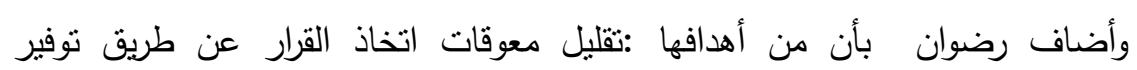

للبيانات،وربطها بمراكز إتخاذ القرار،وتوفير البيانات والمعلومات للمستفيدين بصورة فورية (رأفت

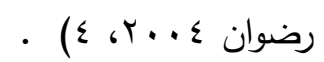

واورد حجازي عدداً من الاهداف وهى :تحسين مستوى الخدمات والتقليل من التعقيدات الإدارية -تخفيض - التكاليف - تحقيق الإفادة القصوى لعملاء المنظمة (عبد الفتاح بيومى لإنى حجازى : بلا تاريخ، 99- 9 • () ) وذكر الحمادي الأهداف الاتية :- بارئ

- - منوير نمط المؤسسة في إجراء المعاملات.

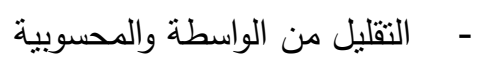
- - معامل المواطن مع المنظمة بشفافية

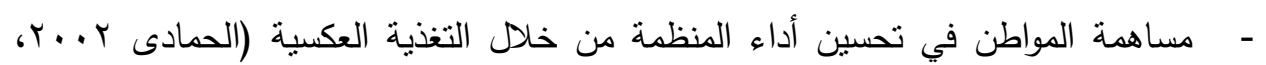

وأكد بكرى أن هناك نوعين من الأهداف للإدارة الإكترونية:

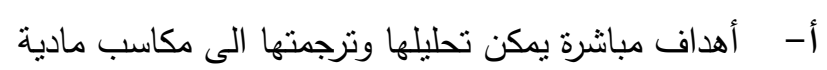

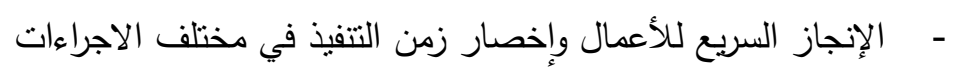

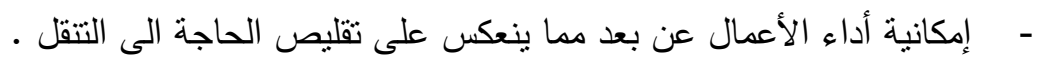
- مقليل مساحات العمل داخل المنظمات . - الحد من استخدام الأوراق في الأعمال الإدارية . 


$$
\text { ب- أهداف عامة غير مباشرة يصعب ترجمتها الى مكاسب مادية ملموسة . }
$$

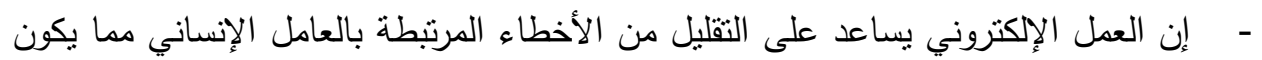

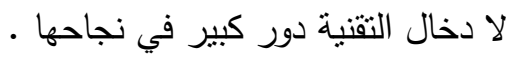

- إن العمل الإككتروني هو الخيار الحتمي الذى بنتح التوافق مع بقية دول العالم الذى تتجه إليه بقوة خاصة المنقدمة منها . - إن العمل الإكتروني يعمل على زيادة وتعزيز القدرة التنافسية للمنظمات بمختلف أنوعها

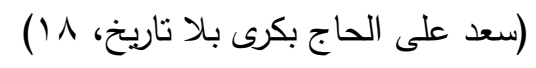

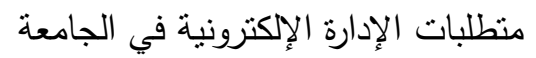

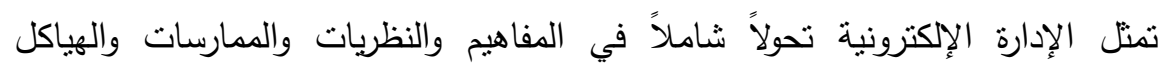
والتشريعات التي تقوم عليها الإدارة التقليدية، وبذلك شأنها شأن أب مشروع يمكن إقامته أو هدف

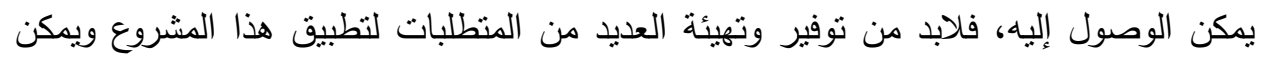
تحديد هذه المنطلبات في النقاط الآتية: المتطلبات التشربعية: يعد هذا الموضوع أكثر موضوعات الإدارة الإكترونية حساسية وأهمية، مع ذلك لا نري في الواقع العربي نشاطًا تشريعيًا يراعي هذه الأهمية، ويمكن القول أن التحديات القانونية للأعمال الإكترونية، هي الإطار الذي جمع كافة تحديات قانون الحاسوب. ويقصد بالعوامل النتريعية هي مجموعة السياسات القانونية واللوائح التنفيذية والتثريعات

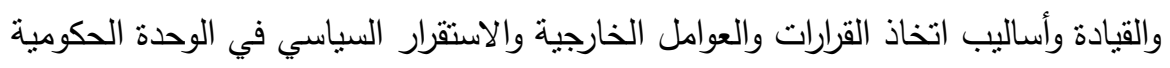
إن القوة لهذه العوامل التشريعية تكمن في البعد الديمقراطي للمشاركة في البيانات

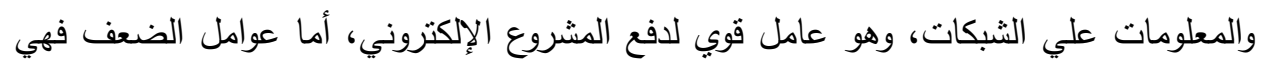
الموازنة الحكومية وقوانين الثبكات الإلكترونية، وعدم وجود خبرة كافية لدي القيادات السياسية، وبطء أساليب اتخاذ القرارات، أما عن الفرص المدكنة فهي في إيجاد تمويل خارجي، والثنفافية

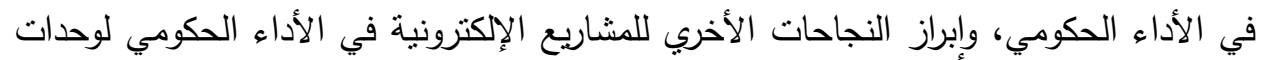

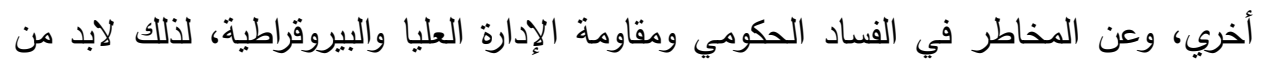

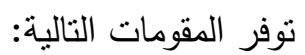

( أ ) وجود الأنظمة والتشريعات المناسبة: تقدم خدمات الإدارة الإلكترونية تحديات جديدة

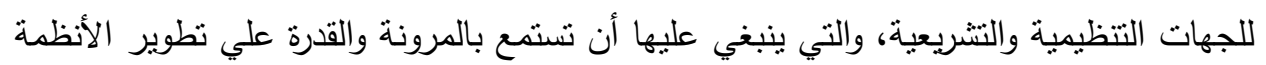
والتثريعات، بحيث تتماشي مع متطلبات الإدارة الإلكترونية. 
والتشريعات المطلوب نوافرها في الإدارة الإلكترونية لمواكبة ذلك التحول، هو إصدار

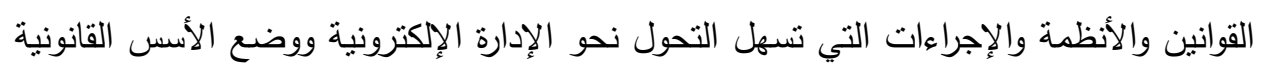

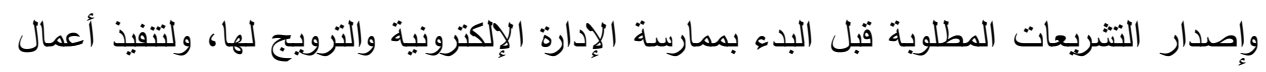

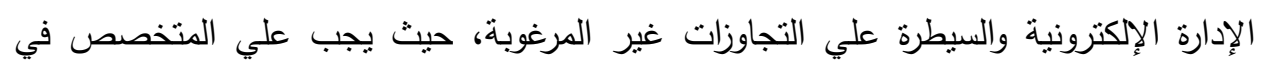
الادارة الجامعية أن يسعوا قبل التعامل مع الإدارة الإككترونية إلي إيجاد بيئة تشريعية ملائمة الإنة

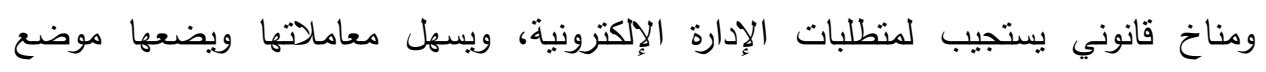
الاعتراف الوطني والدولي إضافة إلي ضمان القضايا الخاصة بتدابير الأمن والحماية والسرية

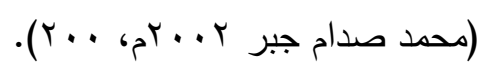

( ب ) توفير القدر الكافي من أمن المعلومات: رغم تقديم الخدمات الحكومية علي ماتي

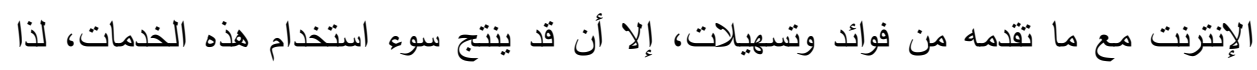

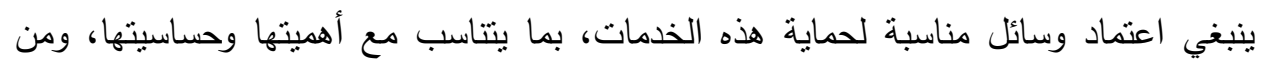

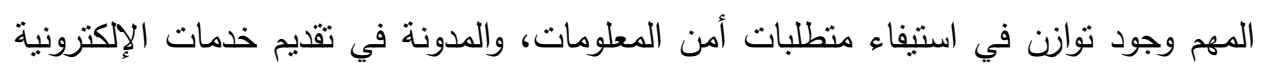

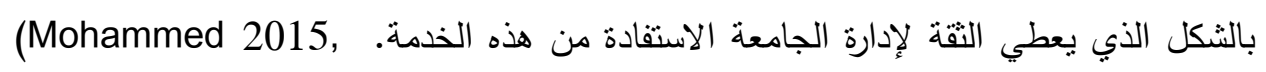

$$
\text { 61-68) }
$$

فالقوانين التي تحمي الخصوصية، تتطلب نوافر تقنية آمنة تكفل خصوصية الأفراد عند

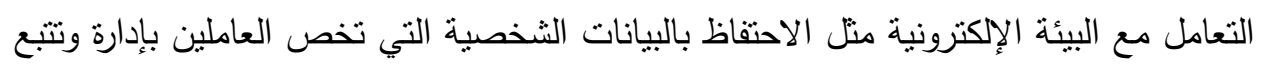

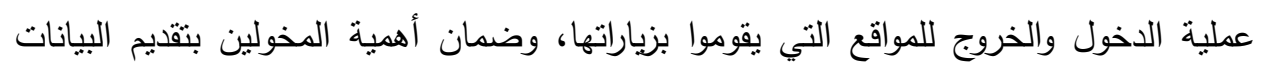
الثخصية. وتعد مسألة أمن المعلومات من أهم مشكلات الإدارة الإلكترونية بمعني أنه يجب الحفاظ

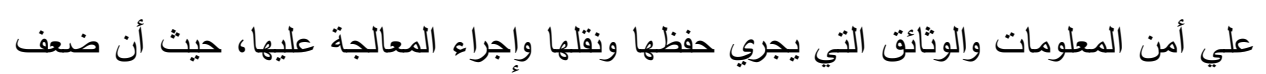
الأمن يعد ضعفًا للنقة. وأمن المعلومات: هو التأكد من أن الأنظمة والبرمجيات تعمل كما هو منوقع وتتتج النتائج المرجوة وتثمل الجوانب القانونية، الممارسات والتطبيقات، التكنولوجيا الأمنية.

$$
\begin{aligned}
& \text { ولتحقيق أمن وحماية المعلومات لابد من: } \\
& \text { - - التوثيق: أي التحقق من مستخدم المعلومات. }
\end{aligned}
$$

- النزاهة: وهو التأكد من أن المعلومات كاملة وصحيحة (Randy Burkhead 2014, 18). - التصديق: أي وصول المعلومات للأشخاص التي تحددهم من قبل الادارة 
- التكامل: أي التأكد من عدم إجراء أي تعديل في المعلومات أثناء نقلها حتي وصولها للمستقبل.

- السرية: وهي عدم إفثاء المعلومات إلي الأطراف غير المصرح لها بالاطلاع عليها

(Ghou 2001, 14)

مما سبق يمكن توضيح مدي أهمية بناء تشريعات قانونية تحتية تشتمل علي اللوائح

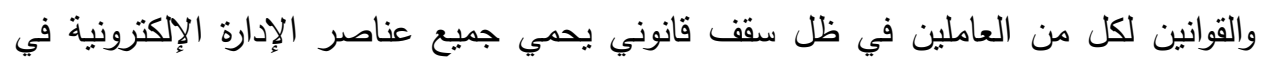

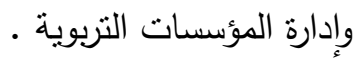

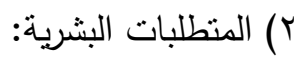

يعد العنصر البشري من أهم العناصر في المؤسسات التربوية، وبدون هذا العنصر لن

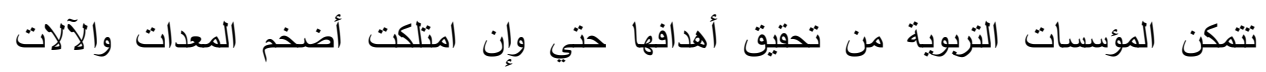

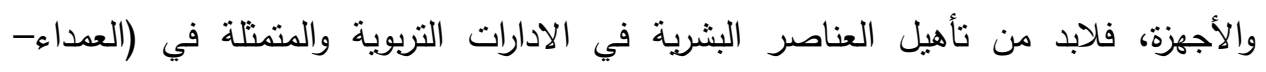

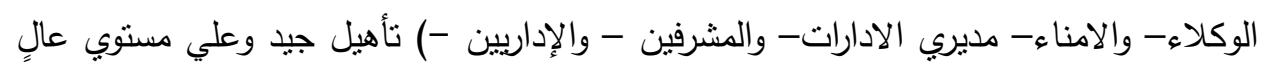
من الكفاءة.

ونظرًا لحجم وتداخل التغيير بين الأفراد سواء العاملين في مدخل الإدارة الإلكترونية أو المتعاملين معها، فإن تصميم وتطبيق نموذج الإدارة الإلكترونية يجب أن يكون منسوبًا بدراسة الإدية

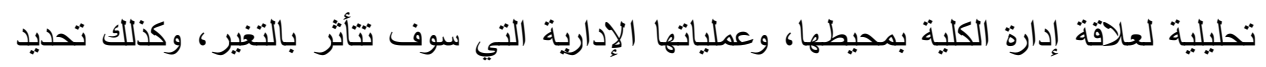

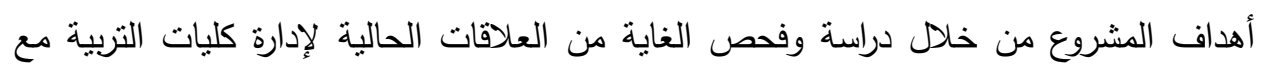

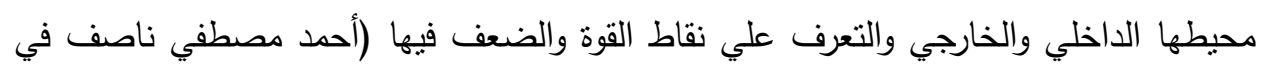

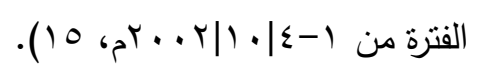

ويعد وجود القوي البشرية المتمثلة في ( العدداء والوكلاء والامناء والإداريين والخبراء

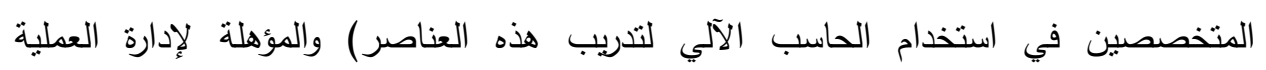

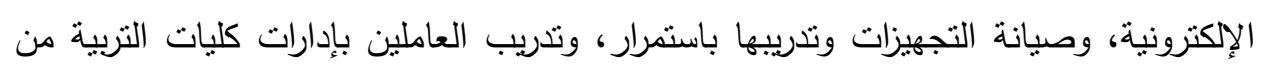

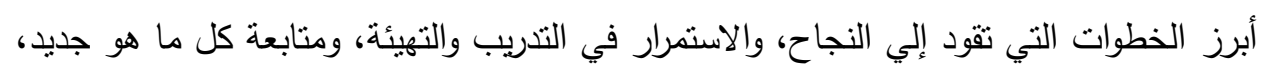

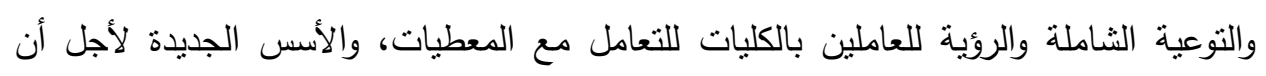

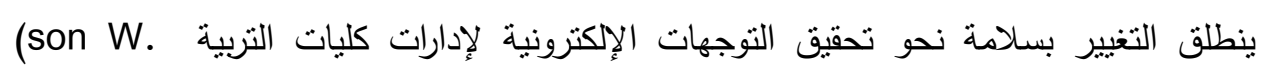

Richardson \& Scott Mclead 2011, 26) 
فالعنصر البشري له دور مهم في الإدارة الإكترونية، فهو المغذي للمعلومات والمستقبل

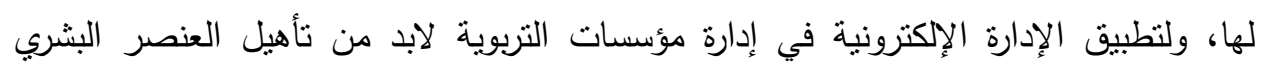
باستمرار، وذلك لرفع مستوي تقافتهم وتقليل مقاومتهم للتغير ويتم ذلك من خلال: - - عقد الندوات والمحاضرات عن تقنية المعلومات. - - إدخال التقنيات الإكترونية كإحدى العناصر الاساسية في الادارات التنربوية. - إجراء ودعم الدراسات والبحوث المتعلقة بالاستفادة من التقنيات المعلومانية.

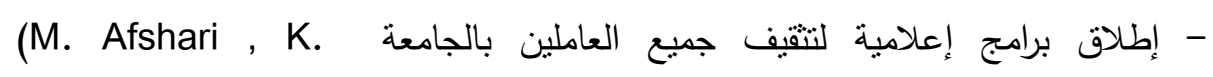
.Abubakar, S.L. Wong 2010, 126) - التوعية الاجتماعية بثقافة الإدارة الإلكترونية من خلال نشر نقافة الإدارة الإكترونية والتني تتتاسب مع مستويات العاملين بالكليات التربوية. - - بناء القدرات بتدريب العاملين بالكليات لكي يتمكنوا من اكتساب المهارات الجديدة والتأقلم

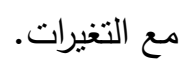
- نتمية الكوادر البشرية من خلال وضع خطة مناسبة للتدريب والتي يتم تكوين فريقها من

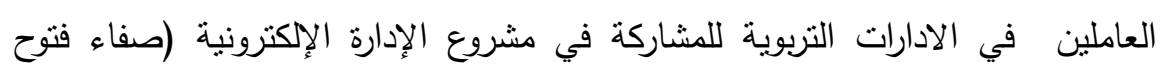

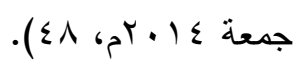
ومن هنا يمكن القول بأن العنصر البشري يعد من أهم منطلبات تطبيق الإدارة الإككترونية

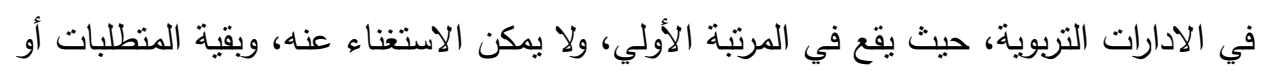

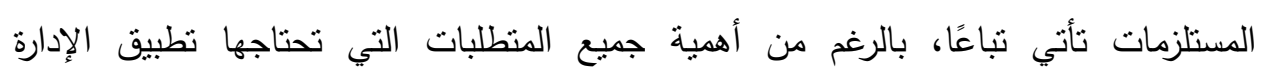

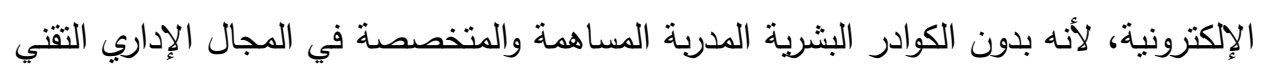

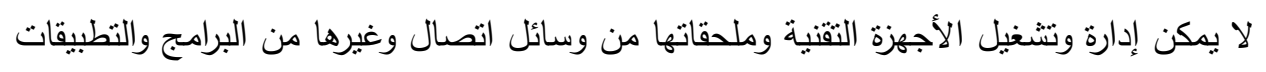

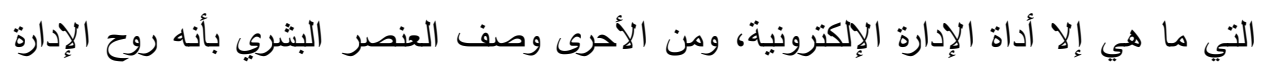
الإكترونية فبدونه لا يمكن إتمام نجاح مشروع الإدارة الإلكترونية في نطوير الجامعة التربية.

$$
\text { 1- المتطلبات التقنية: }
$$

تعد المتطلبات التقنية من العوامل الرئيسية، التي قد تعوق أو تأخر مشروعات الإدارة

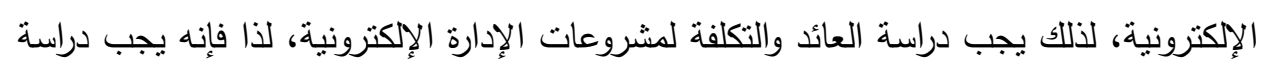

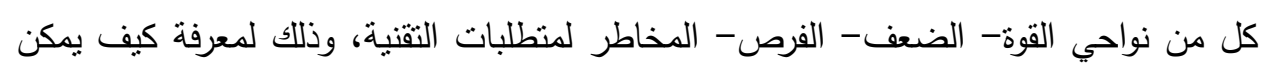
تخطي هذه التحديات لضمان النجاح في وضع دراسة علمية ومالية لمشاريع الإدارة الإكترونية. 
ويقصد بالمنطلبات التقنية توفير وسائل تكنولوجيا الاتصال التي تمكن من عمل البنية للإدارة الإككترونية والمكونة من الحاسب الآلي وبرمجياته وشبكات المعلومات ووسائل الاتصال. وتعد الإدارة الإكترونية أسلوب إداري حيث يهدف إلي تطوير أداء المؤسسات التربوية

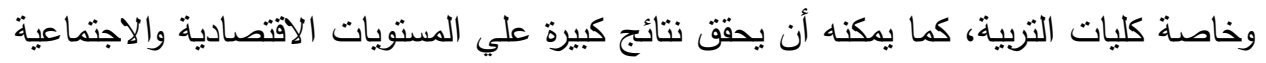
والسياسية، ولكن هذا الأسلوب الحديث يتطلب نوفير البني التحتية الملائمة لإقامة مشروع الإدارة الإلكترونية، وتلعب التقنية الإككترونية دور كبير في عملية الإدارة الإلكترونية، وخاصة في مجال

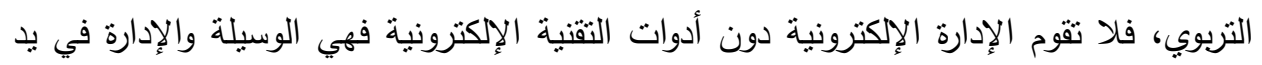
الإدارة التربوية لتتفيذ أدوارها في التحويل الإلكتروني لعملية الإدارة. في ضوء ما سبق يمكن القول بأن المتطلبات التقنية تتحصر في ثلاث شبكات الإدرات الإنترنت،

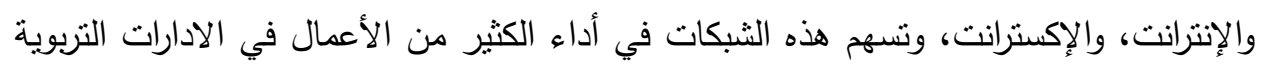

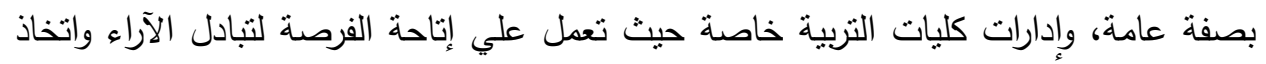

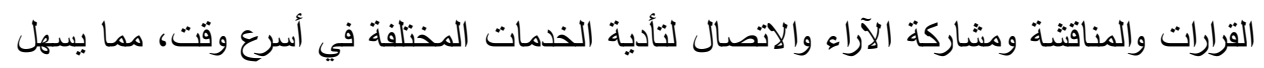
علي الإدارة من نأدية أعمالها في أقل وقت مدكن وتكاليف أقل.

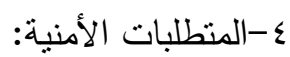

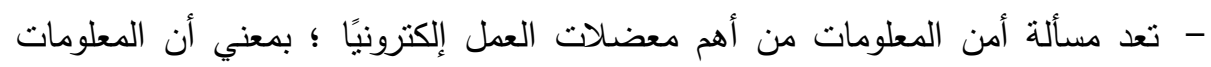

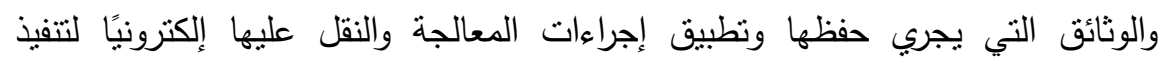

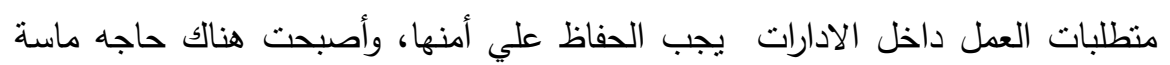

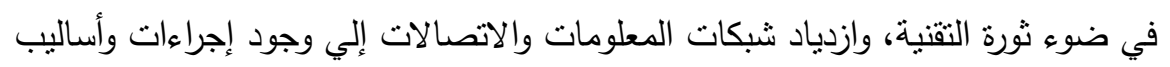
أمنية تساعد علي حماية بيانات ومعلومات الادارة من الاختراق.

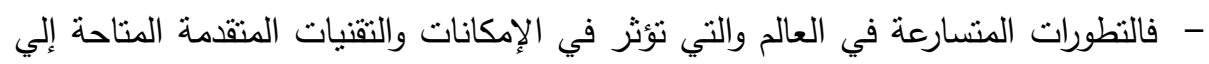
خرق منظومات الحواسيب بغية السرقة أو تدمير المعلومات مما أدي إلي التفكير الجدي الإني

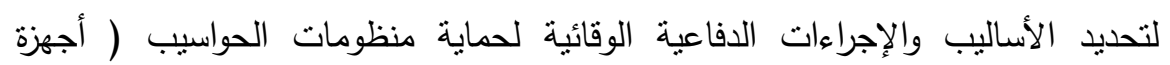

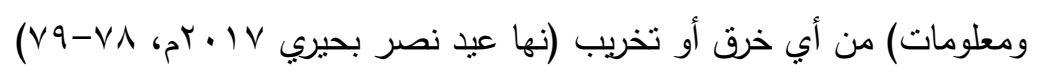
- وفي نفس الصدد يجب تأمين حماية وخصوصية الادارات داخل الكليات خاصة اديب ادارة شئون الطلاب وادارة الدراسات العلبا للبحوث ، وحماية البيانات الخاصة بالبات والباحثين والطلاب ، وإدارة المورد البشرية حيث تحتوى على بيانات ومعلومات عن اعضاء هيئة التدريس والاداريين فيجب تحديد مجموعة من القواعد التي تحكم خصوصية البيانات والمعلومات وجودتها وتكاملها. 
- - ولتطبيق أمن المعلومات في إدارات كليات التربية وتقليص التأثيرات السلبية علي استخدام

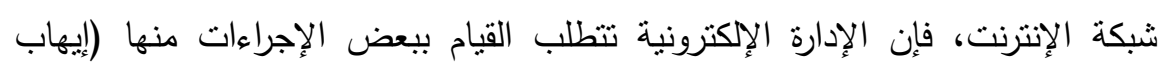

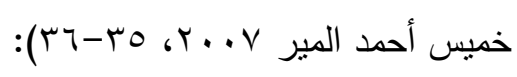

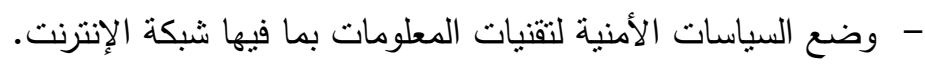

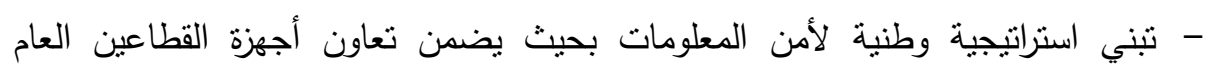
والخاص.

- - وضع اللوائح والقوانين التنظيمية الني تحد من السطو الإكتروني وانتهاكات خصوصية المعلومات في الإدارة الإلكترونية. تطوير أدوات التشفير في البرمجيات الحديثة وخاصة تللك المتعلقة بخدمات الإنترنت لتمكين المستخدم للمحافظة علي سرية تعاملاته عبر الثبكة، وكذلك التوسع في استخدام البطاقة الذكية التي يمكن من خلالها إجراء المعاملات الخدمية. وهناك عدة منطلبات أخري لحماية أمن نظم المعلومات وهي (Yasutsu GU Kuroda) 2005, 0) يجب علي الجامعة دعم أمن نظم المعلومات لديها، وأن توكل هذه المسئولية لأشخاص محددين في الإدارة. تحديد الحماية اللازمة لنظم التشغيل والتطبيقات المختلفة. تحديد آليات المراقبة والتفتيش لنظم المعلومات والثبكات الحاسوبية. تشفير المعلومات التي يتم حفظها وتخزينها ونقلها علي ملف الوسائط.

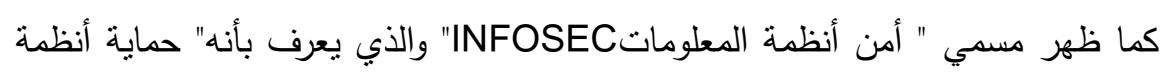
المعلومات ضد وصول أي شخص غير مرخص، أو تعديل المعلومات أثناء حفظها ومعالجتها

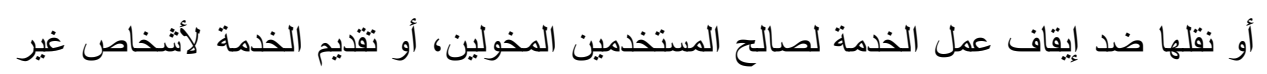

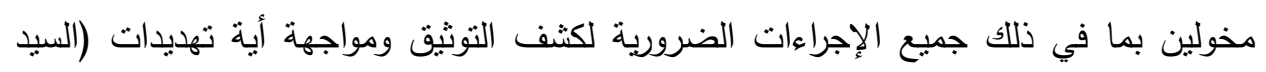

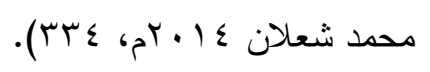
وهناك مجموعة من الوسائل والأساليب والمعدات لحماية المعلومات من السرقة والانتهاك عبر شبكات الاتصالات ومنها ما يلي منوعة من لونائ اعتماد نقاط تدقيق في البرامج لتسجيل المراحل المختلفة التي تمر بها كل عملية تراسل. السبطرة علي خطوط تتاقل البيانات ووضع التحضير اللازم لحماية التتاقل. وضع أجزة إلكترونية لتحس محاولات سرقة المعلومات. 
توثيق أساليب استخدام خطوط تناقل البيانات ضمن الوثائق القياسية كمركز الحاسبة

تحديد كلمات المرور للاخول إلي البرامج وتغييرها دوريًا. استخدام كلمات مرور معقدة حتي يصعب الحصول عليها. توزيع البيانات علي مواقع متعددة داخلية وخارجية. ملاءمة موقع الحاسوب وكفاءة مستلزمات التشغيل.

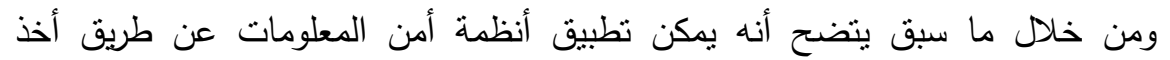

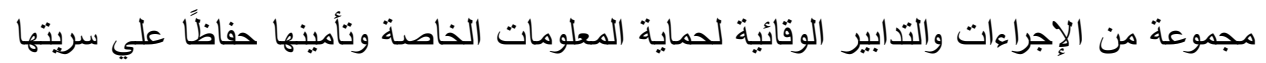
عن طريق التشفير تشفير المعلومات التي ينم حفظها علي جهاز الحاسب، تغيير كلمة pass word الإلكتروني لضمان ضبط حضور وانصراف العاملين بالكلية . وهذا يؤدي إلي توفير الأمن الإكتروني والسرية الإلكترونية وتأمين المراسلات ولصنون

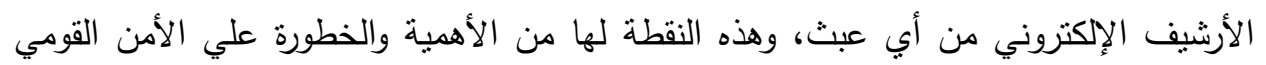

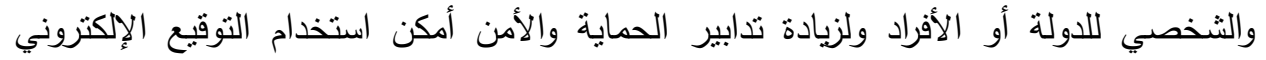

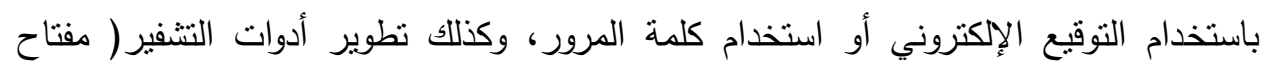

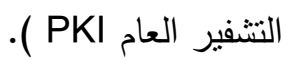
ومن هنا يمكن القول أن أنظمة أمن المعلومات ووسائل تأمين المخاطر الإلكتروني يعمل

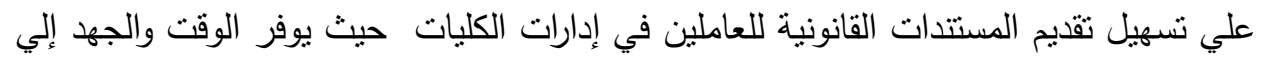
جانب الحرص علي الخصوصية للمنعاملين. المتطلبات المالية:

يتعلق هذا العامل بطرق التمويل وأساليب خفض التكاليف والنموذج المحاسبي والإداري للمشروع، ويعد مشروع الإدارة الإلكترونية من المشروعات الضخمة والتي تحتاج إلي أموال

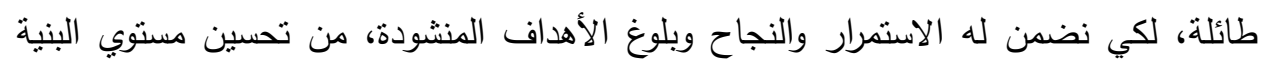

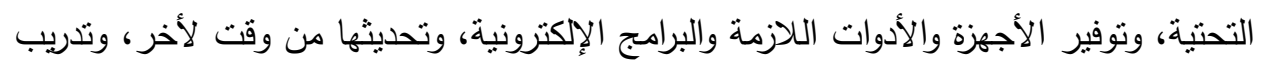

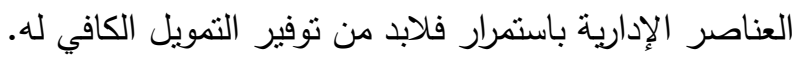

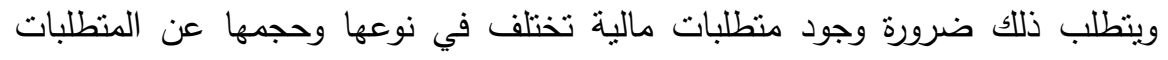

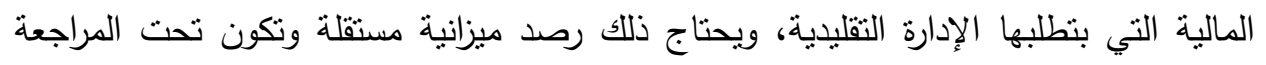

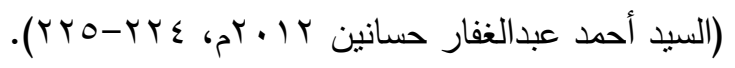


وتعد المتطلبات المالية من العوامل الرئيسية التي قد نعوق أو تؤخر تطبيق الإدارة

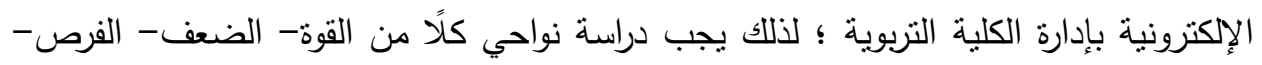
المخاطر ، ولذلك يجب نوافر مجموعة من الضوابط الحاكمة والخاصة بالمنطلبات المالية لضمان الضان تطبيق الإدارة الإكترونية بإدارات الكليات وذللك كما يلي:

وجود برنامج زمني محدد لمراجعة احتياجات الجهاز من المنطلبات المالية والتغبرات التي

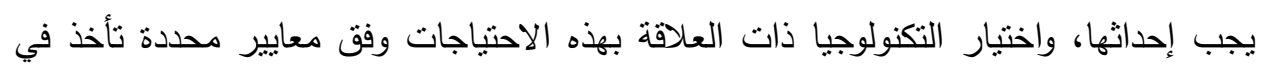
الاعتبار التطورات التكنولوجية الحديثة (Paul (Phristy 2002, 67). وجود قاعدة بيانات متكاملة وموحدة ومترابطة لكافة أنشطة الادارية، وتحديد سير

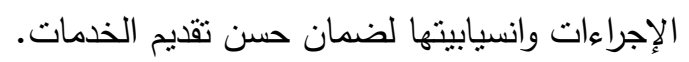
وجود القدرات الفنية من العاملين، والقادرة علي التعامل مع الإنترنت، لضمانئن الضمان تخفيض التكلفة لتطبيق الإدارة الإككترونية. وضع خطة استراتيجية لهذا التطبيق ووضع أولويات ومراحل تتفيذها وتوزيع الأدوار علي

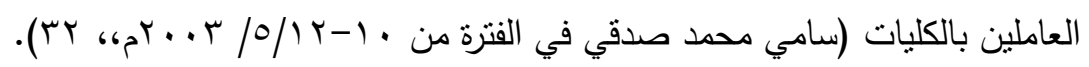
وضع نظام لمراجعة ومتابعة وتقييم الأداء وفقًا للخطط الاستراتيجية والتنفيذية.

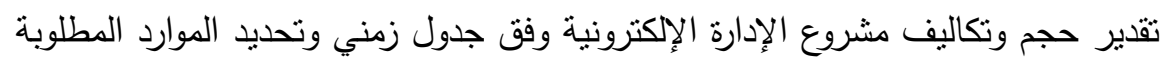

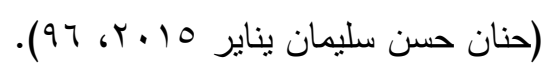

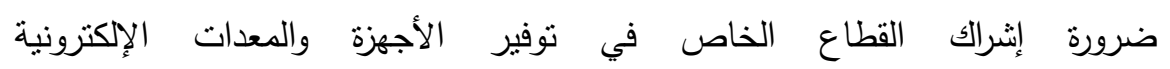
.(VandyKgibson 2016, 30)

زيادة المخصصات المالية لبرامج التدريب للقيادة الادارية في مجال الإدارة الإلكترونية.

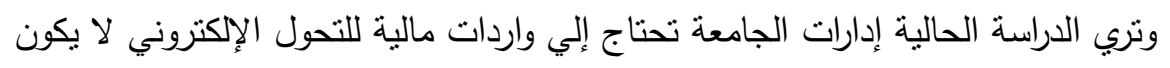
مصدرها فقط من الوزارة، ولكن يمكن توفيرها بطرق أخري منها:

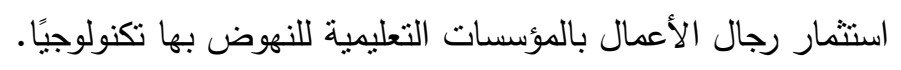

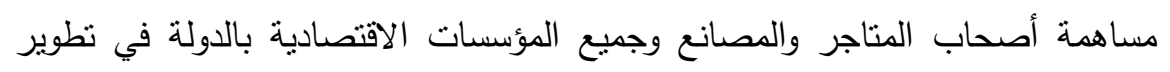

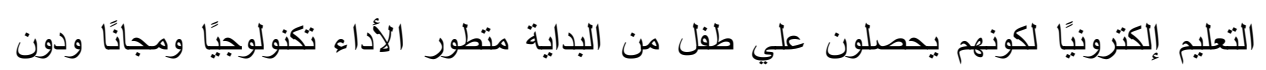
المساهمة في إعداده، ومن الواجب دفع جزء من تكاليف إعداد هذا الطفل وفق منطلبات · النطوير 


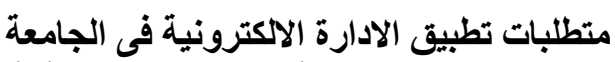

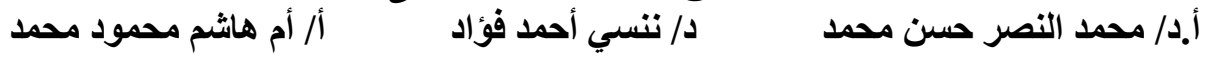

لذلك يعد المتطلب المالي هو الجانب الاقتصادي في الإدارة الإلكترونية، حيث يعتبر أحد

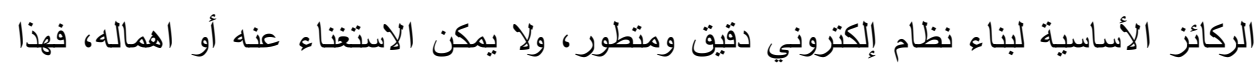

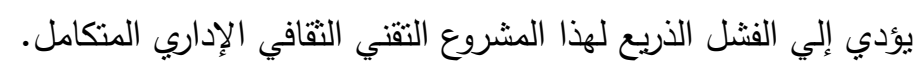
الخلاصة إلية

بناءً علي ما سبق يمكن القول بأن توفير هذه المنطلبات جميعها ضرورة لا غني عنها

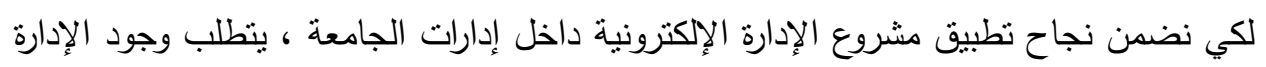

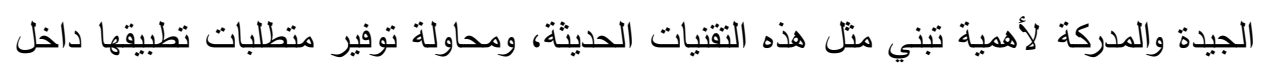
إدارات الكليات والتصدي لكل العقبات التي تعترض بنيتها، ويجب تتمية الوعي التقافي لتطبيق

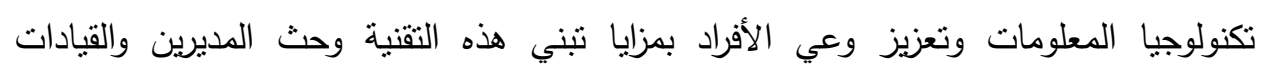
وتدرييهم لتحقيق النطبيق الفعال للإدارة الإلكترونية. 
أبوبكر محمود الهوش(T . . Y). لحكومة الالكترونية الواقع والافاق. القاهرة: مجموعة

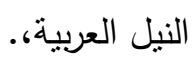
أحمد محمد غنيم.(؟ . ب) الادرة الاكترونية أفاق الحاضر وتطلعات الدستقبل. المنصورة: المكتبة العصرية.

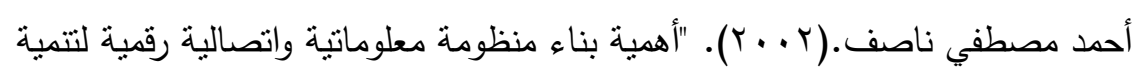

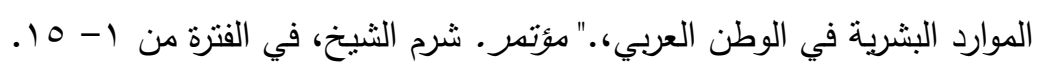

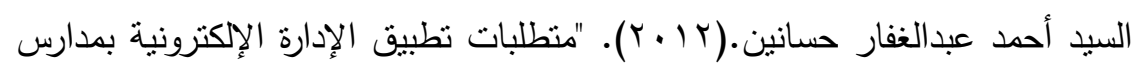
التعليم الثانوي الفني نظام الثلاث سنوات في مصر ومدي مساهمتها في تجويد العمل الإنل

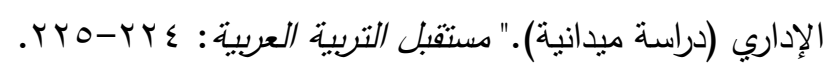

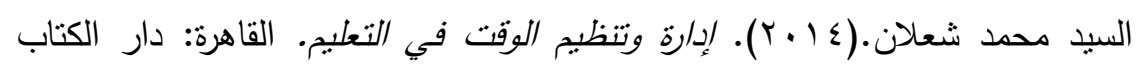
الحديث.

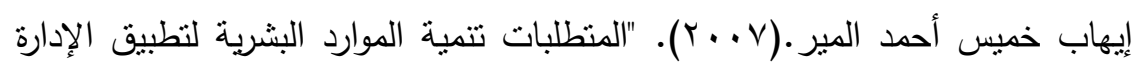

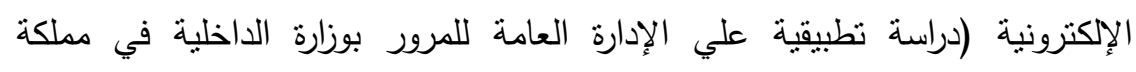

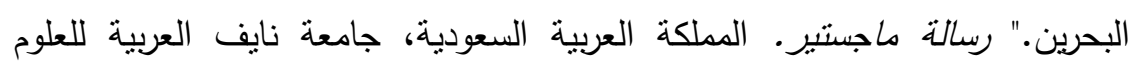

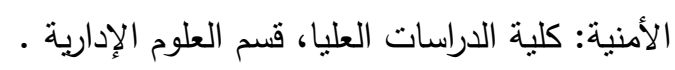

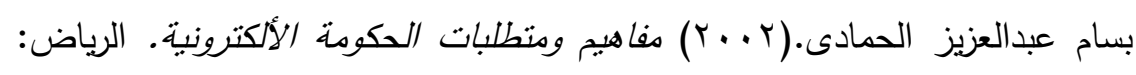
معهد الأدارة العامة.

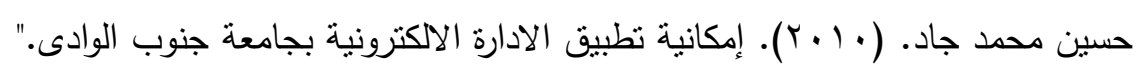

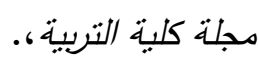

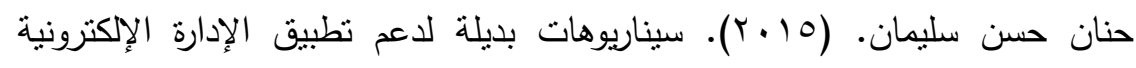

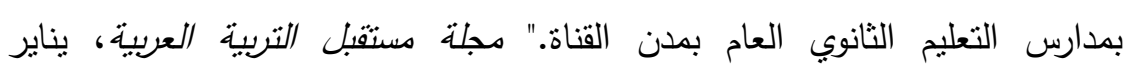

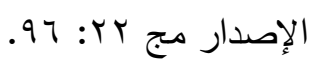

رأفت رضوان.(ع ..ب). الادرة الالكترونية ـ القاهرة: مركز المعلومات ودعم اتخاذ القرار ،.

سعد على الحاج بكرى.. الدعلوماتية والمستقبل،الرياض، دار اليمامة،صر1ا. ـ بلا تاريخ. 


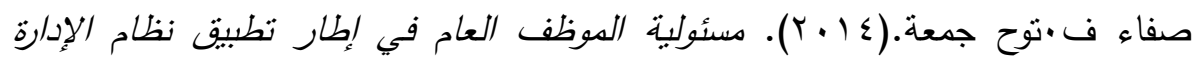

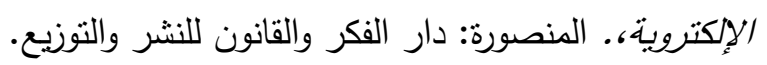

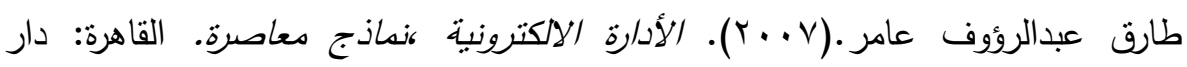
السحاب. عبد العزيز أحمد داود.(ع ( ب). لادرارة التعليمية والادارة الددسية. الاسكندرية: دارالمعرفة الجامعية،. عبد الفتاح بيومى حجازى. "النظام القانونى لحماية الحكومة الالكترونية،دار الفكرالجامعى،

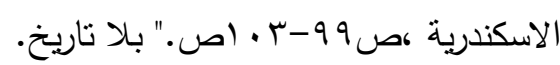

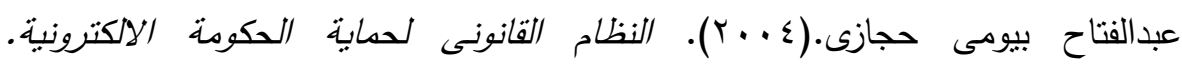

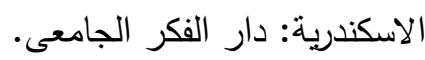

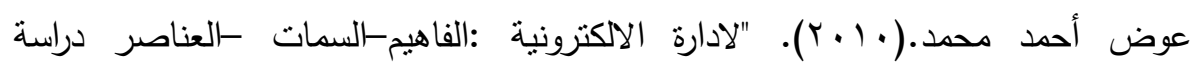

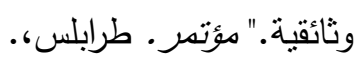

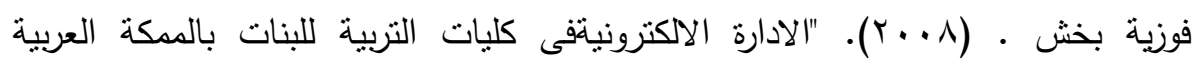
السعودية في ضوء التحويلات المعاصرة." رسالة دكتواره ،غبر منشوره. مكه المكرمة:

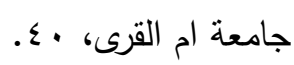
محمد بن هلال الكسار . "نجاح تطبيق التعاملات الالكترونيثبشركة الاتصالات السعودية." رسالة ماجستير. مقدمة الى المجلس كلية إدارة ، بلا ناريخ.

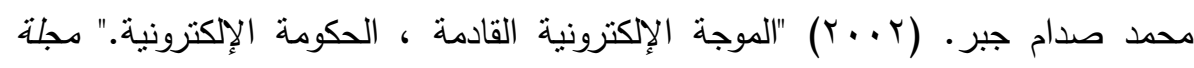

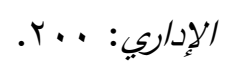

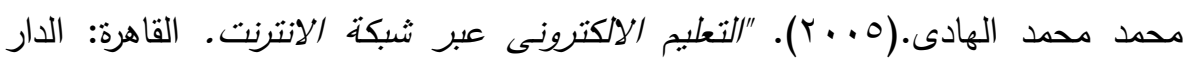
المصرية اللبنانية. نادية أيوب. (ع . . ץ)."الإدارة الالكترونية." مؤتتر. الرياض: الجمعية السعودية للادارة،. ك

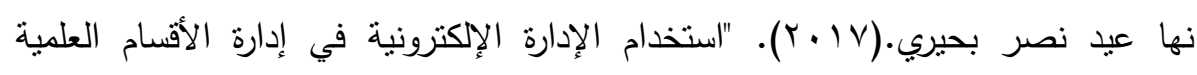

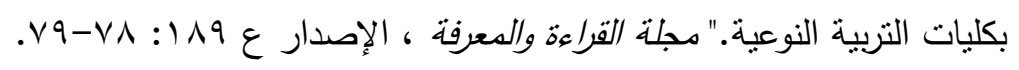

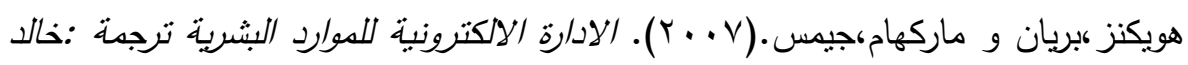

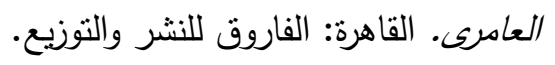


\&Mike, (2003). Charles K. G/s Catalyst for E-Government Development. Washington,.

Ghou. "Trust Vs Security in Government Convergence,( 2001) Symposium E- Government Experience and Applications, Addawha.". 4.

Hortomw.fores.( 2001). "The message of the media the Risks and Opporturities of Migrating pre-eletronic Government information." Britush Journalof Educational Technology. feb,. 58.

M. Afshari , K. Abubakar, S.L. Wong.( 2010). "Principals Level of Computer Use and some Contributing Factors, International Journal of Education and Information Technologies,.".

Mohammed, Eyadat.(2015) . Higher Education Administrators Roles in Fortification of Information Security Program.". 61-68.

Paul ,Christy.( 2002). " U.S.E- E- Government in: Simplified Delivery of Services to Citizens", Washington: U.S. Dept. of Commerce, 2002, P.67. .".

Randy Burkhead. (2014)": Aphenomeno logical Study of Information Security incident Experienced by information Security Professionals Providing Corporate Information Security Incident Management , PhD, Capella University, United States, October, P.18.".

Seyff'Nshaban-Nejad'A. "Automat,Conceptual Analysis of user Requirements With theREquirements Engineering Assistance DIngnostic(READ)Tool,(2008)." international Conference On sSoftware Engineering Research,Management,and Applications (SERA),. California: los Alamitos,. 
متطلبات تطبيق الادارة الاكترونية فى الجامعة

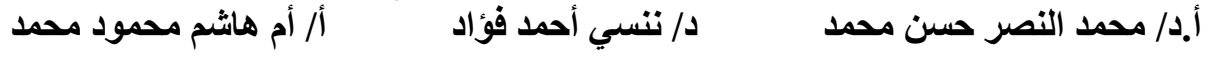

son W. Richardson \& Scott Mclead.(2011). " Technology Leadership in Native American Schools, Journal of Research in Rural Education, Vol. 26, Issue 7, 2011.

VandyKgibson, Jennie. (2016)." K-12 Educational Technology Implementations; Adelphi Study, PhD, Walden University, P.30.". Yasutsu GU Kuroda. (2005)." Jun Kamada, Shoko Iwase, Bintat Su Noda, Etsuo Ono: "Electronic data Storage apparatus with key Management Function and Electronic data Storage Meothed,.". 